\title{
Multivitamin and dietary supplements, body weight and appetite: results from a cross-sectional and a randomised double-blind placebo-controlled study
}

\author{
Geneviève C. Major ${ }^{1}$, Eric Doucet ${ }^{2}$, Mélanie Jacqmain ${ }^{1}$, Myriam St-Onge ${ }^{1}$, Claude Bouchard ${ }^{3}$ \\ and Angelo Tremblay ${ }^{1} *$ \\ ${ }^{1}$ Division of Kinesiology, Department of Social and Preventive Medicine, Laval University, Québec, G1K 7P4, Canada \\ ${ }^{2}$ School of Human Kinetics, University of Ottawa, Ottawa, Canada \\ ${ }^{3}$ Pennington Biomedical Research Center, Baton Rouge, Louisiana, USA
}

(Received 15 May 2007 - Revised 28 August 2007 - Accepted 21 September 2007 - First published online 1 November 2007)

Two studies were conducted to compare characteristics of consumers and non-consumers of vitamin and/or dietary supplements (study 1 ) and to assess the effect of a multivitamin and mineral supplementation during a weight-reducing programme (study 2). Body weight and composition, energy expenditure, and Three-Factor Eating Questionnaire scores were compared between consumers and non-consumers of micronutrients and/or dietary supplements in the Québec Family Study (study 1). In study 2, these variables and appetite ratings (visual analogue scales) were measured in forty-five obese non-consumers of supplements randomly assigned to a double-blind 15-week energy restriction $(-2930 \mathrm{~kJ} / \mathrm{d})$ combined with a placebo or with a multivitamin and mineral supplement. Compared with non-consumers, male consumers of vitamin and/or dietary supplements had a lower body weight $(P<0.01)$, fat mass $(P<0.05)$, BMI $(P<0.05)$, and a tendency for greater resting energy expenditure $(P=0.06)$. In women, the same differences were observed but not to a statistically significant extent. In addition, female supplements consumers had lower disinhibition and hunger scores $(P<0 \cdot 05)$. In study 2 , body weight was significantly decreased after the weight-loss intervention $(P<0 \cdot 001)$ with no difference between treatment groups. However, fasting and postprandial appetite ratings were significantly reduced in multivitamin and mineralsupplemented women $(P<0.05)$. Usual vitamin and/or dietary supplements consumption and multivitamin and mineral supplementation during a weight-reducing programme seems to have an appetite-related effect in women. However, lower body weight and fat were more detectable in male than in female vitamin and/or dietary supplements consumers.

Obesity: Weight loss: Micronutrients: Energy expenditure: Appetite

Above the fundamental roles of physical activity and a macronutrient-balanced diet in the maintenance of a healthy body weight, evidence is pointing toward other dietary factors, admittedly of a lower impact range, that could affect energy balance on a long-term basis and therefore represent an avenue worth considering under obesity treatment circumstances. $\mathrm{Ca}$ is a good example of this, as low consumption of this micronutrient has been shown to be inversely associated with body weight and adiposity in many studies ${ }^{(1-3)}$. More recently, it was observed in a large cohort of 15655 individuals that overweight or obese men and women who had a high consumption of multivitamins, vitamin $\mathrm{B}_{6}$, vitamin $\mathrm{B}_{12}$ or $\mathrm{Cr}$ had gained less weight than those who had not consumed these supplements over 8-12 years ${ }^{(4)}$.

How vitamins and minerals could be implicated in the regulation of body energy stores is not known. For instance, one could propose that they influence the control of food intake through their roles in neurotransmitter synthesis and regulation in the central nervous system. Vitamins $\mathrm{C}$ and $\mathrm{B}_{6}$ are good examples of this, since they are respectively involved in the hydroxylation and decarboxylation of tryptophan for the synthesis of serotonin ${ }^{(5)}$ which is known to control food intake through the melanocortin pathways ${ }^{(6)}$. Low status of vitamin $\mathrm{B}_{6}$ and its consequent decrease in brain serotonin synthesis ${ }^{(7)}$ could result in an increased appetite and presumably food intake and favour a positive energy imbalance. On the other side of the equation, the role of micronutrients as enzyme cofactors necessary for energy transformation within cells ${ }^{(5)}$ suggests that they could also influence the regulation of energy expenditure. In support to these hypothesis, Singh et al. have shown that vitamins $\mathrm{C}$ and $\mathrm{E}$ deficiency was a risk factor for higher percentage body fat and central obesity in Indian men ${ }^{(8)}$. Moreover, high percentages of vitamin $\mathrm{C}$ and $\mathrm{B}_{2}$ deficiency ${ }^{(9)}$, lower bioavailability of vitamin $\mathrm{D}^{(10)}$, lower serum vitamins $\mathrm{A}, \mathrm{C}$ and $\mathrm{E}^{(11)}$ and folic acid concentrations ${ }^{(12)}$ have been found in overweight and obese individuals compared with non-obese subjects. Interestingly, high serum folic acid level was also recently found to be a significant predictor of body-weight loss in morbidly obese patients $^{(13)}$. Finally, an effect of vitamin $\mathrm{C}$ status ${ }^{(14)}$ and of

Abbreviations: AUC, area under the curve; CS, consumers; FFM, fat-free mass; FM, fat mass; MMS, multivitamin + mineral supplement; NCS, non-consumers; REE, resting energy expenditure.

* Corresponding author: Dr Angelo Tremblay, fax +1 418656 3044, email Angelo.tremblay@kin.msp.ulaval.ca 
$\mathrm{Cr}$ supplementation on lipid oxidation and fat-mass (FM) loss ${ }^{(15,16)}$ have been observed in intervention studies.

Taken together, these results suggest that a certain level of availability of vitamins and minerals might influence energy balance regulation and, thus, that an adequate intake could be associated with lower body weight or even determine the success of weight-reducing programmes. In order to investigate this issue, we report data from two separate studies. The objective of study 1 was to determine whether regular consumers (CS) of vitamin and/or dietary supplements were characterised by lower body weight and adiposity values than non-consumers (NCS) of these supplements using data from the Québec Family Study ${ }^{(17)}$. The aim of study 2 was to assess in a different group of participants the effect of a weight-loss intervention, combined with either a multivitamin + mineral supplement (MMS) or with a placebo on bodyweight and FM loss, energy expenditure and appetite.

\section{Methods}

Study 1

Adult men ( $n$ 267) and women (n 320) aged 20-65 years with complete data from the dietary questionnaire (explained in the next section) were selected among the subjects who participated in phase 2 (1991-8) of the Québec Family Study ${ }^{(17)}$. Families of French descent from the greater Québec City area were recruited to participate in this study which received approval from the Laval University Medical Ethics Committee.

Vitamins and dietary supplements. A questionnaire was used to gather dietary information. One of the questions of interest for this study was as follows: 'Do you consume vitamin/dietary supplements?' Since this was the only question asked to record the participants' supplement consumption habits, the dose and the type of vitamins and/or dietary supplements cannot be addressed in this study. The present study therefore pertains to differences between consumers (CS) and NCS of vitamins and/or dietary supplements.

Three-day dietary record and physical activity diary measurement. Dietary habits were determined by a $3 \mathrm{~d}$ dietary record which has been previously shown to provide reliable results ${ }^{(18)}$. All subjects were requested to record their dietary intake during two week days and one weekend day. Nutritionists explained to each subject how to accurately complete the forms. All subjects were supplied with a balance, measuring cups and spoons to facilitate the measuring procedures. A nutritionist reviewed the records together with subjects during an interview. The Canadian Nutrient File ${ }^{(19)}$ was used to assess macro- as well as micronutrient content of foods. Daily physical activities were evaluated with a $3 \mathrm{~d}$ physical activity diary, as previously described ${ }^{(20)}$. Briefly, subjects recorded the number of 15 min periods during $24 \mathrm{~h}$ that they were engaged in activities classified on a 1-9 scale, 1 corresponding to activities of very low energy expenditure such as sleeping and 9 to activities of very high energy expenditure such as running. The $3 \mathrm{~d}$ mean of the number of periods in activities 7 to 9 (activity periods) was used as an indication of physical activity practice.

Eating behaviour measurements. A subgroup of participants completed the Three-Factor Eating Questionnaire ${ }^{(21)}$ as validated for the French population ${ }^{(22)}$. Since this questionnaire was included in the Québec Family Study only at the end of the second phase, data from only 119 men and 174 women were available. The Three-Factor Eating Questionnaire evaluates 'dietary restraint', which measures the actual restrictive eating as well as the intention to restrain eating, 'disinhibition', which measures how easily external factors, that is, environmental events and emotional reactions, disinhibit the control of eating, and 'susceptibility to hunger', which measures the ability to cope with the sensation of hunger ${ }^{(23)}$. The Three-Factor Eating Questionnaire has been shown to have acceptable reliability and validity ${ }^{(21,24)}$.

Anthropometric measurements. Body weight was measured with a standard beam scale. Body density was determined by hydrodensitometry ${ }^{(25)}$. The closed circuit He-dilution method ${ }^{(26)}$ was used to assess the residual lung volume. The Siri formula ${ }^{(27)}$ was used to estimate the percentage of body fat from body density. FM was calculated from the percentage of body fat and total body weight while fat-free mass (FFM) was estimated as the difference between FM and body weight.

Measure of resting energy expenditure. Resting energy expenditure (REE) was measured early in the morning while participants were in a fasted state ( $12 \mathrm{~h}$ overnight fast). Subjects were asked to refrain from physical activity on the day before this measurement. Indirect calorimetry was performed over a $30 \mathrm{~min}$ period through an open-circuit system with a ventilated hood. Data from the last $10 \mathrm{~min}$ of this measurement period were used for the calculation of respiratory quotient and REE. Gas analyses were assayed with an IR $\mathrm{CO}_{2}$ analyser (Ametek CD-3A; Thermox Instruments Division, Pittsburgh, PA, USA) and an IR $\mathrm{O}_{2}$ analyser (Ametek S-3A; Thermox Instruments Division). Analysers were calibrated before each test. The Weir formula ${ }^{(28)}$ was used to determine the energy equivalent of $\mathrm{O}_{2}$ volume.

Statistical analysis. Statistical analyses were performed using SAS software (version 9.1.2; SAS Institute, Cary, NC, USA). Since most of the participants were from three generations of the same family ${ }^{(17)}$, analyses were performed to verify whether there were generation $\times$ supplement consumed status interaction effects and none were found. All subjects were thus pooled together for further analyses although sexes were analysed separately. A one-way analysis of covariance (CS and NCS) taking into account potential covariates (age, height, daily energy intake, percentage dietary fat and activity periods) which have been shown to affect energy balance and/or body-weight control was performed for body weight, FM, FFM, fat percentage and BMI. A one-way ANOVA (CS and NCS) was performed on all other dependent variables. Differences were considered as significant at $P<0.05$ and data are presented as mean values and standard deviations.

\section{Study 2}

Screening. Study 2 was approved by the Laval University Ethics Committee and participants were recruited through diverse media sources such as local newspapers, radio stations and email communications. A sample of sixty-three individuals coming from the Québec City metropolitan area met the study inclusion and exclusion criteria which were as follows: aged 25-45 years, BMI $30-40 \mathrm{~kg} / \mathrm{m}^{2}$, good health, 
waist circumference $\geq 90 \mathrm{~cm}$, stable body weight during 6 months before the study, premenopausal, less than $1 \mathrm{~h} /$ week of continuous physical activity, normal blood pressure values, normal blood glucose levels, normal thyroid hormone levels, non-smoker, no use of medication that could potentially interfere with the study's objectives and no use of vitamin and mineral supplements 6 months before the beginning of the study. Breast-feeding or pregnant women, verified by a urine-based pregnancy test, were excluded from the study.

Participants came to the laboratory for a screening evaluation in order to confirm their eligibility and for explanation of the study consent form. During this visit, blood samples were collected after a $12 \mathrm{~h}$ overnight fast to measure a biochemical profile. Body weight, height and blood pressure were also measured during this visit. Another session was fixed for a medical examination and for explanation of the $3 \mathrm{~d}$ dietary record by a nutritionist (as described for study 1). Fasting blood samples were taken and a $75 \mathrm{~g}$ oral glucose tolerance test over $3 \mathrm{~h}$ was also performed.

Protocol. Following the screening procedures, forty-five obese otherwise healthy men and women were initially enrolled and randomised in a double-blind manner to receive the MMS or the placebo coupled to a 15-week energy restriction. MMS capsules were the Premium Multi-Cap with EsterC from Quest, Canada (composition of the supplement can be found at www.questvitamins.com), and placebo was lactose monohydrate in gelatine capsules. Dosage was one tablet taken before breakfast. Among the initial participants, five dropped out (three placebo and two MMS); four because of personal reasons and one became pregnant.

The sequence of measurements happened as follow and is described in more detail in the following paragraphs. Measurements were spread over two consecutive days. On day 1, REE and respiratory quotient were measured in the fasting state; appetite ratings were assessed before and after a standardised breakfast test and participants were asked to fill in the ThreeFactor Eating Questionnaire. On day 2, $24 \mathrm{~h}$ energy expenditure was measured. Day 1 and 2 measurements were realised at baseline (week 0) and were repeated at the end of the 15 -week intervention (week 15).

Weight-loss intervention. The subjects followed a nonmacronutrient-specific energy-restricted diet for 15 weeks. Prescribed daily energy intake was determined by subtracting $2930 \mathrm{~kJ}(700 \mathrm{kcal})$ from the daily energy expenditure calculated by multiplying the REE by an activity factor of 1.4. A $3 \mathrm{~d}$ dietary record was also used to estimate energy and macronutrient intake of each subject. Following the baseline visit (week 0), a nutritionist explained to the participants how to reach the targeted daily $2930 \mathrm{~kJ}(700 \mathrm{kcal})$ non-macronutrient-specific energy deficit using the food exchange system for diabetics from the Association Diabète Québec ${ }^{(29)}$. During this visit, treatment tablets (MMS or placebo) were given to participants who started the energy restriction and the consumption of the treatment tablets the next morning. The intervention lasted 15 weeks, during which participants met the nutritionist every 2 weeks. In order to assess compliance to the weight-reducing programme, a count of remaining treatment tablets, a $24 \mathrm{~h}$ dietary recall assessed with the nutritionist and visual analogue scales evaluating satisfaction with the diet, hunger, and rigor in following the treatment were filled in by the participants during the interview. On the week between these meetings, participants received a phone call from the nutritionist to answer any questions and ensure that participants were following treatment. Each staff member and participants were blinded to treatment assignment for the duration of the study.

Anthropometry. Height, body weight and waist circumference were determined following the procedures recommended at the Airlie Conference ${ }^{(30)}$, and BMI was then calculated. FM, FFM and percentage of fat were determined as described in the Study 1 methods section.

Resting and $24 \mathrm{~h}$ energy expenditure. REE was measured by indirect calorimetry after a $12 \mathrm{~h}$ overnight fast and a $24 \mathrm{~h}$ period without alcohol consumption and intense physical activity. Participants had to arrive in the morning at the laboratory and to keep an activity level as low as possible in between their wake-up time and their arrival to the laboratory. A questionnaire was filled in by the subjects upon their arrival to ensure they were meeting these criteria. After resting for $15 \mathrm{~min}$, expired gas collection was performed through a mouthpiece for $15 \mathrm{~min}$ while the nose was clipped during the whole measurement. $\mathrm{O}_{2}$ and $\mathrm{CO}_{2}$ concentrations were determined by non-dispersive IR analysis (Uras $10 \mathrm{E}$; Hartmann \& Braun, Frankfurt, Germany) whereas pulmonary ventilation determination was assessed with an S430A measurement system (KL Engineering, Ventura, CA, USA). The Weir formula ${ }^{(28)}$ was used to determine the energy equivalent of $\mathrm{O}_{2}$ volume. The determination of substrate oxidation was assessed through the calculations previously described by Frayn $^{(31)}$ while assuming that protein oxidation contributes $10 \%$ of total energy expenditure measured under these conditions.

The next day, $24 \mathrm{~h}$ total energy expenditure was measured with a whole-body indirect calorimeter, which has been shown to provide highly reproducible data in our laboratory ${ }^{(32)}$. Subjects came back to the laboratory early in the morning and had to have respected the same criteria for fasting, alcohol consumption and physical activity as for the REE measurement. During this stay, subjects were maintained in energy balance by using the REE performed at the initial visit and by extrapolating this value over a $24 \mathrm{~h}$ period and then multiplying this value by an activity factor of 1.32 . The same energy intake was maintained for the two measurements of $24 \mathrm{~h}$ energy expenditure (weeks 0 and 15 ). Moreover, the nutrient composition of the diet (daily food quotient 0.85), the sedentary lifestyle pattern (watching television, computer use, reading, etc) and the meal pattern, as well as the period of sleep, were also standardised in each session. It was not permitted to eat or drink any other foods than those provided and therefore no foods or beverages containing caffeine were allowed during the metabolic chamber stay. Sleeping metabolic rate was also measured in the chamber and was determined as the mean of the two consecutive hours of the night when the subject had the lowest $\mathrm{O}_{2}$ consumption. This value was then extrapolated over $24 \mathrm{~h}$. Women were tested between days 0 and 8 of their menstrual cycle, because energy metabolism-related factors have been shown to be affected by sex steroid levels ${ }^{(33)}$.

Standardised breakfast and appetite ratings. A standardised breakfast which has previously been described ${ }^{(34)}$ was served to participants after a $12 \mathrm{~h}$ overnight fast. The energy 
Table 1. Characteristics of regular consumers and non-consumers of supplements in study 1

(Mean values and standard deviations)

\begin{tabular}{|c|c|c|c|c|c|c|c|c|c|c|c|c|c|c|}
\hline & \multicolumn{7}{|c|}{ Men } & \multicolumn{7}{|c|}{ Women } \\
\hline & \multicolumn{3}{|c|}{ Consumers } & \multicolumn{3}{|c|}{ Non-consumers } & \multirow[b]{2}{*}{$P$} & \multicolumn{3}{|c|}{ Consumers } & \multicolumn{3}{|c|}{ Non-consumers } & \multirow[b]{2}{*}{$P$} \\
\hline & $n$ & Mean & SD & $n$ & Mean & SD & & $n$ & Mean & SD & $n$ & Mean & SD & \\
\hline Age (years) & 51 & 41.4 & 14.8 & 216 & 40.9 & 13.9 & 0.82 & 105 & 41.3 & $13 \cdot 7$ & 215 & 38.5 & 13.0 & 0.08 \\
\hline Body weight $(\mathrm{kg})^{*}$ & 51 & $75 \cdot 0$ & $15 \cdot 5$ & 216 & $82 \cdot 3$ & $19 \cdot 4$ & 0.009 & 105 & 67.0 & 14.6 & 215 & $70 \cdot 1$ & 21.5 & 0.40 \\
\hline BMI $\left(\mathrm{kg} / \mathrm{m}^{2}\right)^{*}$ & 51 & 24.9 & 4.6 & 216 & $27 \cdot 4$ & 6.3 & 0.008 & 105 & $26 \cdot 2$ & 5.7 & 215 & $27 \cdot 1$ & $8 \cdot 3$ & 0.38 \\
\hline Fat mass $(\mathrm{kg})^{\star}$ & 51 & $16 \cdot 1$ & 9.7 & 216 & 20.9 & $13 \cdot 4$ & 0.02 & 105 & 22.5 & 10.9 & 215 & 24.2 & $15 \cdot 9$ & 0.47 \\
\hline Fat-free mass $(\mathrm{kg})^{\star}$ & 51 & 59.0 & 7.8 & 216 & 61.4 & 8.3 & 0.04 & 105 & 44.5 & 5.5 & 215 & 45.9 & $7 \cdot 1$ & 0.31 \\
\hline Fat $(\%)^{*}$ & 51 & $20 \cdot 2$ & 8.0 & 216 & 23.7 & 9.1 & 0.01 & 105 & 32.0 & $9 \cdot 0$ & 215 & 31.8 & 10.9 & 0.90 \\
\hline Resting energy expenditure $(\mathrm{kJ} / \mathrm{kg}$ per $\mathrm{d})$ & 50 & $92 \cdot 6$ & $5 \cdot 3$ & 216 & 89.1 & 11.8 & 0.06 & 104 & 83.6 & $13 \cdot 2$ & 213 & $86 \cdot 2$ & $15 \cdot 2$ & 0.13 \\
\hline Activity periods $(n) \dagger$ & 49 & 4.0 & 5.5 & 207 & 3.6 & 5.4 & 0.72 & 99 & $2 \cdot 2$ & 3.3 & 207 & 1.5 & $2 \cdot 8$ & 0.07 \\
\hline Energy intake $(\mathrm{kJ} / \mathrm{d})$ & 51 & $11427 \cdot 8$ & $2272 \cdot 7$ & 215 & $11423 \cdot 2$ & 2958.9 & 0.99 & 105 & $8159 \cdot 6$ & 1841.0 & 210 & $8568 \cdot 8$ & $2028 \cdot 8$ & 0.08 \\
\hline Dietary fat $(\%)$ & 51 & 34.4 & 5.6 & 215 & 34.6 & 6.4 & 0.87 & 105 & 33.3 & $6 \cdot 2$ & 210 & 34.9 & $6 \cdot 1$ & 0.03 \\
\hline Dietary carbohydrates (\%) & 51 & 47.6 & 7.6 & 215 & $46 \cdot 2$ & 6.6 & 0.20 & 105 & 48.7 & $7 \cdot 0$ & 210 & $47 \cdot 3$ & $6 \cdot 0$ & 0.06 \\
\hline Dietary proteins (\%) & 51 & $15 \cdot 4$ & 2.5 & 215 & $16 \cdot 0$ & 3.1 & $0 \cdot 19$ & 105 & $16 \cdot 3$ & 3.0 & 210 & $16 \cdot 2$ & $3 \cdot 2$ & 0.72 \\
\hline Alcohol (\%) & 51 & $2 \cdot 7$ & $5 \cdot 0$ & 215 & $3 \cdot 2$ & 5.4 & 0.49 & 105 & 1.7 & 3.0 & 210 & $1 \cdot 7$ & 3.4 & 0.96 \\
\hline Dietary restraint & 29 & 5.9 & 3.4 & 90 & 5.5 & 3.6 & 0.59 & 65 & 7.9 & $5 \cdot 0$ & 109 & 8.3 & 4.6 & 0.67 \\
\hline Disinhibition & 29 & 4.6 & 3.5 & 90 & 4.8 & 2.9 & 0.80 & 65 & 6.0 & 3.4 & 109 & $7 \cdot 1$ & 3.7 & 0.05 \\
\hline Susceptibility to hunger & 29 & 3.9 & 3.9 & 90 & 4.4 & $3 \cdot 2$ & 0.51 & 65 & 3.4 & 3.0 & 109 & 4.7 & 3.6 & 0.02 \\
\hline
\end{tabular}

Adjusted for age, height, daily energy intake, percentage dietary fat and activity periods.

tMean daily number of $15 \mathrm{~min}$ periods of activity level $7-9$ assessed with a physical activity diary. 
I ।

का

\section{$\bar{b} \bar{c} \overline{0}$}

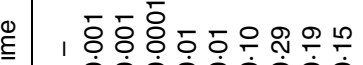
$\dot{0} \dot{0} \dot{0} \dot{0} \dot{0} \dot{0} \dot{0} \dot{0} \dot{0}$ œ 항ำ $\dot{0} \dot{0}$

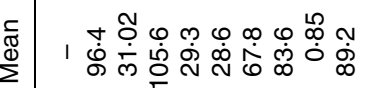

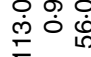

का 离

ฮ $\stackrel{\varpi}{2}$ में

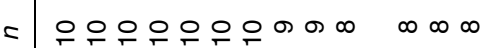
க) ।

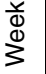

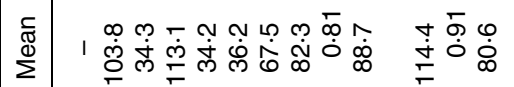
$\frac{\pi}{2}$
$\frac{\pi}{2}$
0
0
0
$\vdots$
3

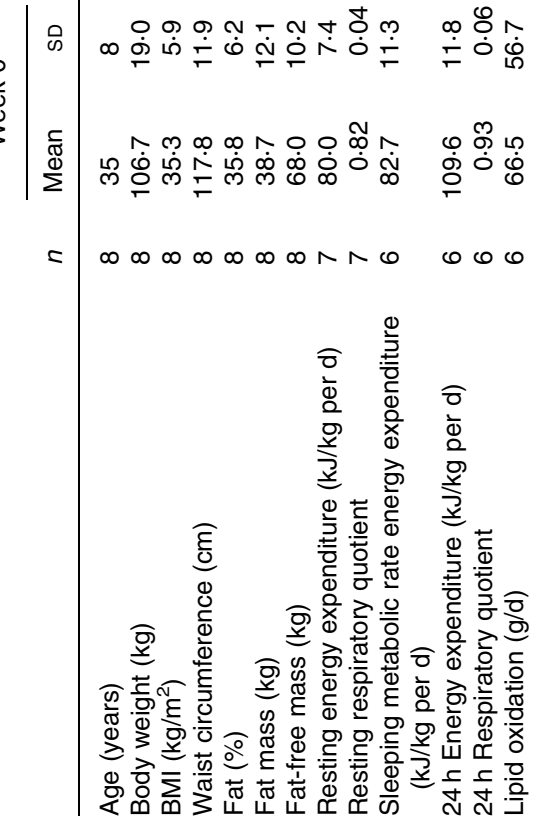

content of the breakfast was $3067 \mathrm{~kJ}(733 \mathrm{kcal})$ and $2506 \mathrm{~kJ}$ $(599 \mathrm{kcal})$ for men and women, respectively, and had a food quotient of 0.85 . All participants were instructed to eat within $30 \mathrm{~min}$ or less. Before, immediately after and every $10 \mathrm{~min}$ for a period of $1 \mathrm{~h}$ after the breakfast, subjects were asked to fill in visual analogue scales adapted from Blundell $\&$ Hill $^{(35)}$. The answer to the following questions were used to determine their 'desire to eat', 'hunger', 'fullness' and 'prospective food consumption', respectively: (1) 'How strong is your desire to eat?' (very weak - very strong); (2) 'How hungry do you feel?' (not hungry at all - as hungry as I have ever felt); (3) 'How full do you feel?' (not full at all very full); (4) 'How much food do you think you could eat?' (nothing at all - a large amount), respectively. Appetite ratings measured before breakfast were considered as the fasting measurement, and appetite ratings in response to the breakfast were evaluated by calculating the post-meal area under the curve (AUC) with the trapezoid method as previously described $^{(36)}$. AUC was calculated considering appetite rating responses at $0,10,20,30,40,50$ and $60 \mathrm{~min}$ after the breakfast. Breakfast was consumed and visual analogue scale measurements performed in the same room kept quiet and away from different visual, hearing and olfactory stimuli that might have influenced the measurements. Under these conditions, visual analogue scale measurements in our laboratory have been shown to be highly reliable both before and in response to a meal ${ }^{(36,37)}$. During this visit, participants were also asked to complete the Three-Factor Eating Questionnaire as described in study 1 .

Statistical analysis. Statistical analyses were performed using SAS software (version 9.1.2; SAS Institute, Cary, NC, USA). A two-way ANOVA with repeated measurements on one factor (time) was used to assess the effects of treatment (placebo and MMS) and time, and their interaction on all dependent variables within each sex. In order to adjust the appetite variables for change in body weight, a two-way ANOVA was repeated using residual scores for appetite ratings and the Three-Factor Eating Questionnaire scores derived from linear regression analysis considering body weight as the independent variable. Three-Factor Eating Questionnaire scores that included unanswered questions were corrected for the specific eating behaviour total score. Differences were considered significant at $P<0.05$ and data are presented as mean values and standard deviations.

\section{Results}

Study 1

Results from study 1 showed that men CS had significantly lower body weight, BMI, FM, percentage body fat and FFM than men NCS after adjustments were made for age, height, daily energy intake, percentage dietary fat and activity periods. Men CS also had a trend toward a greater REE expressed per kg body weight compared with men NCS $(P=0.06)$. The same trend was found for anthropometric measurements between CS and NCS in women but the differences were less pronounced and statistically non-significant. Variables related to food intake as well as daily physical activity level were all comparable between both groups of men (Table 1). However, the CS group of women had a 


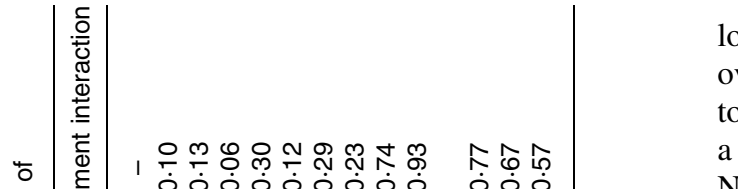

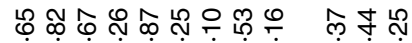

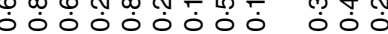

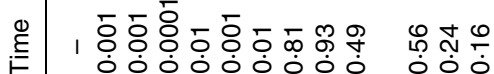

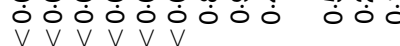

Q

离

焉 |

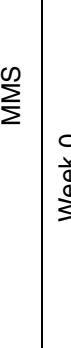
12

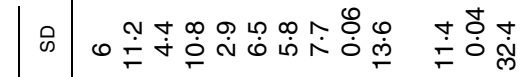
๘

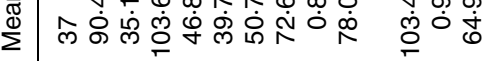

C FFFFFFFF_으 으으우 ம 帝 3

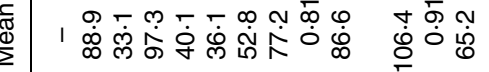

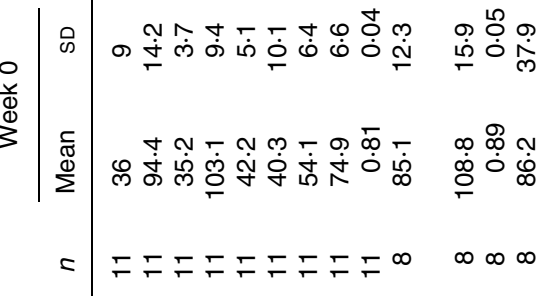

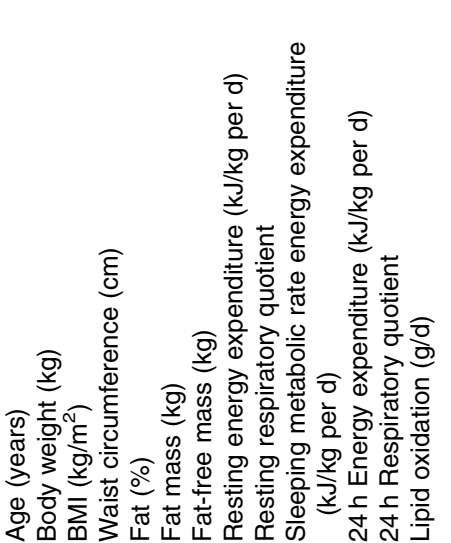

lower fat intake and tended to be older and to have a lower overall energy intake, greater carbohydrate consumption and to be more physically active (Table 1). Women CS also had a significantly lower disinhibition and hunger scores than NCS women $(P<0.05)$, while in CS men the slightly lower scores observed for these variables were not statistically different from those in NCS men.

\section{Study 2}

Baseline daily vitamin and mineral consumption, assessed with the $3 \mathrm{~d}$ dietary record, was similar between placebo and MMS groups in both men and women (results not shown). Anthropometric variables, REE and $24 \mathrm{~h}$ energy expenditure mean values are presented in Tables 2 and 3 for men and women, respectively. Means for these variables were similar in MMS and placebo groups before intervention. Body weight, BMI, waist circumference, FM and percentage of fat were significantly decreased at week 15 in men and women in both MMS and placebo groups. In women only, a significant decrease in FFM was also observed, with no difference between MMS and placebo groups.

Appetite ratings measured in the fasting state before breakfast and postprandial appetite rating AUC measured after the breakfast are presented in Table 4. In men, no significant between-group difference was observed for these variables. In women, baseline value for fasting desire to eat was significantly lower in the placebo than in the MMS group. However, a significant time $\times$ treatment interaction effect was observed for this variable, revealing a significant decrease in the MMS group and a non-significant increase in the placebo group. Significant time $\times$ treatment interaction effects were observed in women for desire to eat, hunger and prospective food consumption AUC, revealing a significant decrease in these variables in the MMS group only, and an AUC value for these three variables that was significantly lower in the MMS group compared with the placebo group at week 15 (Table 4). These differences were observed after statistical adjustments for body-weight change. In both men and women, a significant increase in dietary restraint and a significant decrease in disinhibition and susceptibility to hunger were observed following the programme with no difference between treatment groups (Table 5).

\section{Discussion}

Results obtained in study 1 showed that men regularly consuming micronutrients and dietary supplements had a lower body weight and FM than men who did not. This agrees with the recently reported lower 8-12 years body-weight gain in overweight or obese CS of multivitamins, vitamins $\mathrm{B}_{6}$, vitamin $\mathrm{B}_{12}$ and $\mathrm{Cr}$ compared with $\mathrm{NCS}^{(4)}$. From a body-weight-regulation standpoint, these observations suggest that a sufficient intake of micronutrients, which have fundamental roles in energy metabolism ${ }^{(5)}$, might be needed to achieve energy balance stability. Sufficient intake of micronutrients could thus be important in the context of obesity treatment, where micronutrient intake may be decreased along with macronutrients during reduced-energy diets ${ }^{(38,39)}$. This hypothesis was investigated in study 2 , and no difference in the changes in body weight, FM, energy expenditure and 
Table 4. Appetite ratings measured before and after a standardised breakfast meal before (week 0) and after (week 15) the weight-loss intervention in study 2 (Mean values and standard deviations)

\begin{tabular}{|c|c|c|c|c|c|c|c|c|c|c|c|c|c|}
\hline & \multicolumn{5}{|c|}{ Placebo } & \multicolumn{5}{|c|}{ MMS } & & & \\
\hline & \multirow[b]{2}{*}{$n$} & \multicolumn{2}{|c|}{ Week 0} & \multicolumn{2}{|c|}{ Week 15} & \multirow[b]{2}{*}{$n$} & \multicolumn{2}{|c|}{ Week 0} & \multicolumn{2}{|c|}{ Week 15} & \multicolumn{3}{|c|}{ Statistical significant effect‡ of } \\
\hline & & Mean & SD & Mean & SD & & Mean & SD & Mean & SD & Time & Treatment & Time $\times$ treatment interaction \\
\hline \multicolumn{14}{|l|}{ Men } \\
\hline Fasting desire to eat $(\mathrm{mm})$ & 8 & $73 \cdot 1$ & 43.9 & $83 \cdot 1$ & 38.4 & 10 & $76 \cdot 8$ & $40 \cdot 7$ & 89.9 & $31 \cdot 0$ & 0.60 & 0.74 & 0.94 \\
\hline Fasting hunger $(\mathrm{mm})$ & 8 & $100 \cdot 8$ & 37.2 & $102 \cdot 0$ & $24 \cdot 3$ & 10 & 99.8 & $37 \cdot 6$ & $105 \cdot 7$ & $32 \cdot 1$ & 0.60 & 0.83 & 0.77 \\
\hline Fasting fullness (mm) & 8 & 23.0 & $17 \cdot 6$ & $32 \cdot 1$ & $17 \cdot 2$ & 10 & $27 \cdot 8$ & $19 \cdot 0$ & $35 \cdot 0$ & 25.8 & 0.08 & 0.60 & 0.84 \\
\hline Fasting PFC $(\mathrm{mm})$ & 8 & $97 \cdot 3$ & $22 \cdot 1$ & $97 \cdot 3$ & 30.9 & 10 & $100 \cdot 4$ & 34.8 & 111.2 & $20 \cdot 6$ & 0.60 & 0.63 & 0.48 \\
\hline AUC desire to eat $(\mathrm{mm} \times \mathrm{min})$ & 8 & 1854 & 1571 & 1740 & 1074 & 10 & 1775 & 1554 & 1985 & 1333 & 0.94 & 0.88 & 0.73 \\
\hline AUC hunger $(\mathrm{mm} \times \mathrm{min})$ & 8 & 2001 & 1490 & 2139 & 1667 & 10 & 1891 & 1522 & 1983 & 1394 & 0.68 & 0.90 & 0.96 \\
\hline AUC fullness $(\mathrm{mm} \times \mathrm{min})$ & 8 & 4895 & 1790 & 5535 & 1726 & 10 & 5875 & 2171 & 5807 & 2161 & 0.82 & 0.45 & 0.44 \\
\hline AUF PFC $(\mathrm{mm} \times \mathrm{min})$ & 8 & 2505 & 1082 & 2226 & 857 & 10 & 3022 & 2518 & 2463 & 1916 & 0.36 & 0.71 & 0.81 \\
\hline \multicolumn{14}{|l|}{ Women } \\
\hline Fasting desire to eat $(\mathrm{mm})$ & 11 & 71.6 & 43.7 & $92 \cdot 1$ & 48.5 & 11 & $116 \cdot 8 \dagger$ & 28.8 & $76 \cdot 4^{*}$ & 39.4 & 0.13 & 0.39 & 0.001 \\
\hline Fasting hunger $(\mathrm{mm})$ & 11 & $81 \cdot 3$ & $45 \cdot 1$ & 86.2 & $45 \cdot 6$ & 11 & $96 \cdot 7$ & 43.8 & $90 \cdot 0$ & 44.5 & 0.69 & 0.60 & 0.74 \\
\hline Fasting fullness (mm) & 11 & 35.6 & 30.4 & 21.8 & $26 \cdot 1$ & 11 & 19.9 & $19 \cdot 3$ & $36 \cdot 4$ & 37.6 & 0.54 & 0.90 & 0.06 \\
\hline Fasting PFC $(\mathrm{mm})$ & 11 & 95.5 & 45.5 & $92 \cdot 1$ & 34.9 & 11 & $110 \cdot 1$ & 30.7 & 88.9 & 38.4 & 0.73 & 0.11 & 0.31 \\
\hline AUC desire to eat $(\mathrm{mm} \times \mathrm{min})$ & 11 & 1184 & 1369 & 1616 & 1593 & 11 & 1548 & 1397 & $900^{*} \dagger$ & 807 & 0.58 & 0.72 & 0.028 \\
\hline AUC hunger $(\mathrm{mm} \times \mathrm{min})$ & 11 & 1398 & 1584 & 1717 & 1974 & 11 & 1562 & 1509 & $1007^{*} \dagger$ & 1081 & 0.33 & 0.62 & 0.048 \\
\hline AUC fullness $(\mathrm{mm} \times \mathrm{min})$ & 11 & 6308 & 1936 & 6390 & 2184 & 11 & 5584 & 2006 & 6905 & 2211 & 0.10 & 0.85 & 0.09 \\
\hline AUF PFC $(\mathrm{mm} \times \mathrm{min})$ & 11 & 2404 & 1925 & 2310 & 2059 & 11 & 1952 & 1490 & $1004^{*} \dagger$ & 941 & 0.029 & 0.23 & 0.028 \\
\hline
\end{tabular}

MMS, multivitamin and mineral supplementation; PFC, prospective food consumption; AUC, area under the curve.

作

Thean value was significantly different from that in the placebo group $(P<0.05)$

Adusted for body-weight change. 
lipid oxidation was observed between obese individuals supplemented with a MMS or with a placebo in the context of a weight-reducing programme. However, the supplementation in micronutrients had a beneficial effect on appetite-rating variables in women as shown by the significantly lower AUC for desire to eat, hunger and prospective food consumption in MMS-supplemented women compared with baseline and compared with the placebo group. A significant decrease in fasting desire to eat was also observed in MMS-supplemented women, although this result could be considered less powerful since the baseline value for this variable was significantly higher in this group compared with placebo. These differences remained significant when change in body weight was taken into account, suggesting that an adequate intake in vitamins and minerals might influence satiety.

Appetite is increased in response to body-weight loss ${ }^{(36,40)}$ due to variations in hormone levels implicated in the regulation of energy balance such as insulin, leptin and corti$\mathrm{sol}^{(36,41,42)}$. Since some vitamins and minerals are involved in the synthesis of these and other peptides and neurotransmitters that control food intake, a decreased micronutrient availability could affect peptide hormone levels and thus interfere with the signalling pathways that control food intake, as was observed in Zn-deprived rats ${ }^{(43)}$. From a more peripheral perspective, it is well known that variations in energy substrate availability can also impact on hunger and energy intake. Studies in animals ${ }^{(44,45)}$ and in human subjects ${ }^{(46,47)}$ have shown that inhibition of glucose utilisation and fatty acid oxidation resulted in an increased appetite and energy intake, as does a decrease in blood glucose concentrations ${ }^{(48,49)}$. Since micronutrients are essential to energy substrate oxidation and must be supplied by the $\operatorname{diet}^{(5)}$, one can speculate that their intake is also regulated. As such, a lower consumption could result in signalling to feeding centres to increase energy intake in order to satisfy the body's micronutrient needs ${ }^{(50)}$. This hypothesis is supported by the recently described evidence for the existence of an appetite for $\mathrm{Ca}$, $\mathrm{Na}, \mathrm{Mg}$ and $\mathrm{Se}^{(51-54)}$, and is concordant with the lower susceptibility to hunger and disinhibition observed in women CS compared with NCS in study 1 . This could also explain the significant decrease in appetite ratings at the end of the programme in MMS women but not in the placebo group in study 2. Interestingly, some studies have shown that postprandial prospective food consumption, which was significantly reduced in MMS women, is the most consistent predictor of energy intake $\mathrm{e}^{(36,55,56)}$. Thus, these results strengthen the plausible role for vitamins and minerals in the control of appetite and ultimately energy intake.

In this regard, the absence of any significant effect of the MMS supplement on body weight, energy expenditure and lipid oxidation in study 2 cannot be ignored. It could perhaps be explained by the fact that participants were not selected on the basis of a low micronutrient intake status. Indeed, vitamin and mineral consumption by the participants was in a normal range before intervention, and the appetite for minerals as described above has been reported mainly in circumstances of deprivation in these minerals ${ }^{(50-54)}$. Moreover, several crosssectional studies have reported a link between a high body weight and intake of a micronutrient when the latter is inadequate or a deficiency is evident ${ }^{(1-3,8,9,11,12,57)}$. In accordance with this, Volpe et al. found no effect from supplementation 
of $\mathrm{Cr}$, an essential trace element involved in energy substrate metabolism ${ }^{(5)}$, on body composition or REE in obese women whose vitamin and mineral consumption was in a normal range before intervention ${ }^{(58)}$. Overall, this suggests that an appetite-modulating effect of vitamin and mineral supplements could be more significant in individuals characterised by inadequate intake in micronutrients.

It is also possible that the energy restriction in study 2 masked the effect that the vitamin and mineral supplementation could have had on body weight. Indeed, all participants were instructed to reduce their energy intake in proportion to their baseline consumption. This could explain, at least partly, why a decrease in body weight above that attributed to the weight-reducing programme was not seen in supplemented individuals, but that a lower body weight was observed in free-living long-term vitamin and/or dietary supplement CS (study 1 and Nachtigal et al. ${ }^{(4)}$ ) in whom no a priori dietary restriction interfered with the proposed micronutrient-induced appetite-reduction effect. Further research in this issue should focus on large groups of individuals characterised by inadequate vitamin and mineral intake.

It is intriguing that in study 1 , the possible influence of vitamin and dietary supplements on body weight was observed only in men (and in women to a lesser extent) while in study 2 , significant appetite effects were observed only in women, as for the suggested behavioural effect in study 1 . In this last study, this could be due to the fact that other factors affecting energy balance and body weight (see Table 1) were not as closely matched in women as they were in men. Moreover, CS women were older and had a significant lower dietary fat intake than NCS women. With respect to study 2 findings, because appetite control is under the influence of central and peripheral as well as behavioural signals and social factors ${ }^{(36,41,42)}$, dietary restraint typically more present in women than in men ${ }^{(57,59)}$ could have influenced appetite ratings. However, in both sexes, changes that occurred during the programme followed the same trend upward for restraint and downward for disinhibition and susceptibility to hunger. Moreover, these changes as well as these variables' scores before and after the programme were similar between treatment groups, suggesting that they probably do not account for the differences in appetite ratings in women and in men. However, it has to be recognised that although we took into consideration the most obvious confounding variables (physical activity, macronutrient composition of the diet), and verified that the education level and total annual familial income was not affecting the results (results not shown), other lifestyle factors we did not measure might have exerted an influence and have partly accounted for the differences between CS and NCS in study 1 . This is especially true for the type and composition of the vitamin and/or dietary supplement in study 1 for which we had no detailed information. Although study 2 was based on a much stronger experimental design to control for potential confounders, the number of participants was low. On one hand this indicates that effects were substantial since statistical significance was achieved despite small group sizes but on the other hand, the present results and conclusions need to be treated with caution unless replicated in larger groups of participants.

\section{Conclusion}

In conclusion, cross-sectional observations have shown that men regularly consuming vitamin and dietary supplements had a lower body weight and FM and tended to have a higher relative RMR compared with men who did not report consuming such supplements, independently from physical activity level and dietary factors. This trend was also seen in women together with a reduced hunger level. A doubleblind randomised controlled study showed no direct evidence that multivitamin and mineral supplementation during a weight-reducing programme in a relatively small number of obese individuals could enhance body-weight and FM loss. However, the multivitamin and mineral supplement was found to significantly decrease appetite ratings in women after weight loss, compared with a placebo group which also lost weight. This therefore suggests that vitamin and mineral supplements could attenuate, in women, the increase in appetite that often accompanies body-weight loss. This issue should be further investigated as should the underlying mechanisms of vitamins and minerals in appetite control.

\section{Acknowledgements}

The study was supported by the Canadian Institutes of Health Research. G. C. M. is the recipient of a training fellowship from the Heart and Stroke Foundation of Canada, the Canadian Diabetes Association and the Canadian Institutes of Health Research. A. T. is partly funded by the Canada Research Chair in Physical Activity, Nutrition and Energy Balance. C. B. is partially funded by the George A. Bray Chair in Nutrition. E. D. is a recipient of a CIHR/MerckFrosst New Investigator Award and CFI/OIT New Opportunities Award. The authors acknowledge Claude Leblanc for his assistance with statistical analyses.

\section{References}

1. Jacqmain M, Doucet E, Despres JP, Bouchard C \& Tremblay A (2003) Calcium intake, body composition, and lipoprotein-lipid concentrations in adults. Am J Clin Nutr 77, 1448-1452.

2. Loos RJ, Rankinen T, Leon AS, Skinner JS, Wilmore JH, Rao DC \& Bouchard C (2004) Calcium intake is associated with adiposity in black and white men and white women of the HERITAGE Family Study. J Nutr 134, 1772-1778.

3. Zemel MB, Shi H, Greer B, Dirienzo D \& Zemel PC (2000) Regulation of adiposity by dietary calcium. FASEB $J$ 14, 1132-1138.

4. Nachtigal MC, Patterson RE, Stratton KL, Adams LA, Shattuck AL \& White E (2005) Dietary supplements and weight control in a middle-age population. J Altern Complement Med 11, 909-915.

5. Groff JL \& Gropper SS (2000) Advanced Nutrition and Human Metabolism, 3rd ed. Belmont, CA: West/Wadsworth.

6. Heisler LK, Cowley MA, Kishi T, et al. (2003) Central serotonin and melanocortin pathways regulating energy homeostasis. Ann N Y Acad Sci 994, 169-174.

7. Anderson GH \& Johnston JL (1983) Nutrient control of brain neurotransmitter synthesis and function. Can J Physiol Pharmacol 61, 271-281.

8. Singh RB, Beegom R, Rastogi SS, Gaoli Z \& Shoumin Z (1998) Association of low plasma concentrations of antioxidant vitamins, 
magnesium and zinc with high body fat per cent measured by bioelectrical impedance analysis in Indian men. Magnes Res 11,3-10.

9. Harnroongroj T, Jintaridhi P, Vudhivai N, Pongpaew P, Tungtrongchitr R, Phonrat B, Changbumrung S \& Schelp FP (2002) B vitamins, vitamin C and hematological measurements in overweight and obese Thais in Bangkok. J Med Assoc Thai 85, $17-25$.

10. Wortsman J, Matsuoka LY, Chen TC, Lu Z \& Holick MF (2000) Decreased bioavailability of vitamin D in obesity. Am $J$ Clin Nutr 72, 690-693.

11. Moor DB, Wartanowicz M \& Ziemlanski S (1992) Blood vitamin and lipid levels in overweight and obese women. Eur J Clin Nutr 46, 803-808.

12. Tungtrongchitr R, Pongpaew P, Tongboonchoo C, Vudhivai N, Changbumrung S, Tungtrongchitr A, Phonrat B, Viroonudomphol D, Pooudong S \& Schelp FP (2003) Serum homocysteine, $\mathrm{B}_{12}$ and folic acid concentration in Thai overweight and obese subjects. Int J Vitam Nutr Res 73, 8-14.

13. Martinez JJ, Ruiz FA \& Candil SD (2006) Baseline serum folate level may be a predictive factor of weight loss in a morbid-obesity-management programme. Br J Nutr 96, 956-964.

14. Johnston CS (2005) Strategies for healthy weight loss: from vitamin C to the glycemic response. J Am Coll Nutr 24, 158-165.

15. Bahadori B, Wallner S, Schneider H, Wascher TC \& Toplak H (1997) Effect of chromium yeast and chromium picolinate on body composition of obese, non-diabetic patients during and after a formula diet (article in German). Acta Med Austriaca 24, 185-187.

16. Crawford V, Scheckenbach R \& Preuss HG (1999) Effects of niacin-bound chromium supplementation on body composition in overweight African-American women. Diabetes Obes Metab 1, 331-337.

17. Bouchard C (1996) Genetic epidemiology, association and sib-pair linkage: results from the Québec Family Study. In Molecular and Genetic Aspects of Obesity, pp. 470-481 [GA Bray and DH Ryan, editors]. Baton Rouge, LA: Louisiana State University Press.

18. Tremblay A, Sévigny J, Leblanc C \& Bouchard C (1983) The reproducibility of a three-day dietary record. Nutr Res 3, $819-830$.

19. Government of Canada (1990) The Canadian Nutrient File. Ottawa: Health and Welfare Canada.

20. Bouchard C, Tremblay A, Leblanc C, Lortie G, Savard R \& Thériault G (1983) A method to assess energy expenditure in children and adults. Am J Clin Nutr 37, 461-467.

21. Stunkard AJ \& Messick S (1985) The three-factor eating questionnaire to measure dietary restraint, disinhibition and hunger. J Psychosom Res 29, 71-83.

22. Lluch A (1995) Identification des conduites alimentaires par approches nutritionnelles et psychométriques: implications thérapeutiques et préventives dans l'obésité humaine (Identification of food intake behaviours by nutritional and psychometric means: implications for prevention and treatment of human obesity). PhD Thesis, University of Nancy, France.

23. Drapeau V, Provencher V, Lemieux S, Despres JP, Bouchard C \& Tremblay A (2003) Do 6-y changes in eating behaviors predict changes in body weight? Results from the Quebec Family Study. Int J Obes Relat Metab Disord 27, 808-814.

24. Laessle RG, Tuschl RJ, Kotthaus BC \& Pirke KM (1989) A comparison of the validity of three scales for the assessment of dietary restraint. J Abnorm Psychol 98, 504-507.

25. Behnke AR \& Wilmore JH (1974) Evaluation and Regulation of Body Build and Composition. Englewood Cliffs, NJ: Prentice-Hall.

26. Meneely EA \& Kaltreider NL (1949) Volume of the lung determined by helium dilution. J Clin Invest 28, 129-139.

27. Siri WE (1956) The gross composition of the body. Adv Biol Med Phys 4, 239-280.
28. Weir JB (1949) New methods for calculating metabolic rate with special reference to protein metabolism. J Physiol 109, $1-9$.

29. Association Diabète Québec (1993) Plan d'Alimentation avec le Système d'Échanges (Plan of Food Exchange System). Montréal, Canada: Groupe Litho Graphique.

30. Harrison GG, Buskirk ER, Carter JEL, Johnston FE, Lohman TG, Pollock ML, Roche AF \& Wilnor J (1988) Skinfold thickness and measurement technique. In Anthropometric Standardization Reference Manual, pp. 39-80 [TG Lohman, AF Roche and R Martorell, editors]. Champaign, IL: Human Kinetics Books.

31. Frayn KN (1983) Calculation of substrate oxidation rates in vivo from gaseous exchange. $J$ Appl Physiol 55, 628-634.

32. White MD, Bouchard G, Buemann B, Almeras N, Despres JP, Bouchard C \& Tremblay A (1996) Reproducibility of 24-h energy expenditure and macronutrient oxidation rates in an indirect calorimeter. $J$ Appl Physiol 80, 133-139.

33. Day DS, Gozansky WS, Van Pelt RE, Schwartz RS \& Kohrt WM (2005) Sex hormone suppression reduces resting energy expenditure and $\beta$-adrenergic support of resting energy expenditure. J Clin Endocrinol Metab 90, 3312-3317.

34. Drapeau V, Blundell J, Therrien F, Lawton C, Richard D \& Tremblay A (2005) Appetite sensations as a marker of overall intake. Br J Nutr 93, 273-280.

35. Blundell JE \& Hill AJ (1986) Paradoxical effects of an intense sweetener (aspartame) on appetite. Lancet i, 1092-1093.

36. Doucet E, St Pierre S, Almeras N \& Tremblay A (2003) Relation between appetite ratings before and after a standard meal and estimates of daily energy intake in obese and reduced obese individuals. Appetite 40, 137-143.

37. Arvaniti K, Richard D \& Tremblay A (2000) Reproducibility of energy and macronutrient intake and related substrate oxidation rates in a buffet-type meal. Br J Nutr 83, 489-495.

38. Grzybek A, Klosiewicz-Latoszek L \& Targosz U (2002) Changes in the intake of vitamins and minerals by men and women with hyperlipidemia and overweight during dietetic treatment. Eur J Clin Nutr 56, 1162-1168.

39. Vasilaras TH, Astrup A \& Raben A (2004) Micronutrient intake in overweight subjects is not deficient on an ad libitum fatreduced, high-simple carbohydrate diet. Eur J Clin Nutr 58, 326-336.

40. Doucet E, Imbeault P, St Pierre S, Almeras N, Mauriege P, Richard D \& Tremblay A (2000) Appetite after weight loss by energy restriction and a low-fat diet-exercise follow-up. Int J Obes Relat Metab Disord 24, 906-914.

41. Blundell JE, Goodson S \& Halford JC (2001) Regulation of appetite: role of leptin in signalling systems for drive and satiety. Int J Obes Relat Metab Disord 25, Suppl. 1, S29-S34.

42. Keim NL, Stern JS \& Havel PJ (1998) Relation between circulating leptin concentrations and appetite during a prolonged, moderate energy deficit in women. Am J Clin Nutr 68, 794-801.

43. Reeves PG (2003) Patterns of food intake and self-selection of macronutrients in rats during short-term deprivation of dietary zinc. J Nutr Biochem 14, 232-243.

44. Friedman MI, Tordoff MG \& Ramirez I (1986) Integrated metabolic control of food intake. Brain Res Bull 17, 855-859.

45. Friedman MI \& Tordoff MG (1986) Fatty acid oxidation and glucose utilization interact to control food intake in rats. Am J Physiol 251, R840-R845.

46. French S \& Castiglione K (2002) Recent advances in the physiology of eating. Proc Nutr Soc 61, 489-496.

47. Kahler A, Zimmermann M \& Langhans W (1999) Suppression of hepatic fatty acid oxidation and food intake in men. Nutrition 15, 819-828.

48. Anderson GH, Catherine NL, Woodend DM \& Wolever TM (2002) Inverse association between the effect of carbohydrates 
on blood glucose and subsequent short-term food intake in young men. Am J Clin Nutr 76, 1023-1030.

49. Campfield LA, Smith FJ, Rosenbaum M \& Hirsch J (1996) Human eating: evidence for a physiological basis using a modified paradigm. Neurosci Biobehav Rev 20, 133-137.

50. Ames BN (2004) A role for supplements in optimizing health: the metabolic tune-up. Arch Biochem Biophys 423, 227-234.

51. McCaughey SA \& Tordoff MG (2002) Magnesium appetite in the rat. Appetite 38, 29-38.

52. Paradis S \& Cabanac M (2005) Calcium deficiency cannot induce obesity in rats. Physiol Behav 85, 259-264.

53. Tordoff MG (2001) Calcium: taste, intake, and appetite. Physiol Rev 81, 1567-1597.

54. Zuberbuehler CA, Messikommer RE \& Wenk C (2002) Choice feeding of selenium-deficient laying hens affects diet selection, selenium intake and body weight. J Nutr 132, 3411-3417.

55. Barkeling B, Rossner S \& Sjoberg A (1995) Methodological studies on single meal food intake characteristics in normal weight and obese men and women. Int $J$ Obes Relat Metab Disord 19, 284-290.

56. Flint A, Raben A, Blundell JE \& Astrup A (2000) Reproducibility, power and validity of visual analogue scales in assessment of appetite sensations in single test meal studies. Int $J$ Obes Relat Metab Disord 24, 38-48.

57. Carmody TP, Brunner RL \& St Jeor ST (1995) Dietary helplessness and disinhibition in weight cyclers and maintainers. Int $J$ Eat Disord 18, 247-256.

58. Volpe SL, Huang HW, Larpadisorn K \& Lesser II (2001) Effect of chromium supplementation and exercise on body composition, resting metabolic rate and selected biochemical parameters in moderately obese women following an exercise program. J Am Coll Nutr 20, 293-306.

59. Provencher V, Drapeau V, Tremblay A, Despres JP \& Lemieux S (2003) Eating behaviors and indexes of body composition in men and women from the Quebec Family Study. Obes Res 11, $783-792$. 